${ }^{1}$ Institut de géographie, Faculté des lettres, Université de Lausanne

${ }^{2}$ Institut universitaire de médecine sociale et préventive, Faculté de médecine,

Université de Lausanne

\title{
Mapping adolescent health and lifestyles in a multi-state country: methodological aspects and first results
}

Summary

Objectives: To explore the feashbilty of a geographical anaysis (mappingl of data from a national adolescent survey.

Methods: Teenagers 15 to 19 years in high school or apprenti. ceship $(N=5275$ boys and 3993 girs) answered a self-admin. stered anomymous questicnnaire targeting heath and lifesy. les. Swikerland was divided in 14 subunts, each one induding at least 400 subjerts: large cantons were isolated by themsel. vas whereas smaller ones were aggregated taking into account common cultural, geographical and health characteristics. To mirimise the mact of sample differences across the cantons, subsamples were weighted according to age, sex, and professional background. For each wariable, the discrevisation of the values in tive classes was perfomed using the threshold approach which maximises intergroup differences and minimises the miragroup diferances.

Results: The andysis suggests diferent paterns of distribu tion depending on the type of varable studied: substanca use differs mosty between urban and rural cantons, whle mentel heath differs beween french and seman-speaking camtons. Conclusions: Whereas most avallable atlases are derved from population-besed data (1.., mortaly rates) this research demonstrates the feasiblity of using self-reported data from schoolbased survey samples. The presentation of data on attractive maps provides unique opportunty for generating hypotheses as to the causes of differences across cantons in a mumpethnic mutticutural county.

Key-Words: Methodology - Health - Lifestyle - Mapping - Switzerland.
The concept of a geography of health is fairly new and has grown rapidly during the last twenty years ${ }^{1-3}$. Mapping, for instance, offers a great deal of information regarding the ecology of diseases as well as the delivery of health services. As such, it constitutes a valuable resource for those professionals in charge of planning health services ${ }^{4}$. Another interesting field of a geography of health is to help experts from various areas generate hypotheses as to why and how health events occur (i.e., correlation between environmental as well as socio-cultural factors and diseases). This approach, however, is associated with several methodological issues, mainly the problem of the choice of indicators as well as their validity. Up to now, most of the work in the field of health geography has used "hard" data such as mortality data ${ }^{5-7}$ or morbidity data from hospitals ${ }^{8}$. These indicators, especially those related to mortality, are of interest because they can be assessed in terms of a nationwide population, they are readily available and usually relatively valid. Using survey results, some researchers ${ }^{9-11}$ have recently turned to attitudes towards health, utilisation of health care structures and lifestyles including those behaviours affecting health such as substance use, sexual behaviour, nutrition habits, sports activity, or exposure to risk. To our knowledge, few researchers until now have attempted to systematically use the results of an adolescent survey to conduct geographical analyses of their health. As mortality rates in this age group remain low - at least in developed countries - it is all the more important to obtain a picture of health and lifestyles because it is during this period that most individuals will engage in behaviour which will influence their wellbeing for the rest of their lives ${ }^{12}$. The spatial analysis of adolescent health allows to raise hypotheses regarding the combined influence of the educational system, cultural habits, and the accessibility to health services and prevention programmes ${ }^{13}$. 
In this respect, Switzerland constitutes a unique platform of observation since it is made up of three distinct language communities; moreover, legislation, school systems, and cultural backgrounds also vary considerably from one Swiss canton to another and may affect adolescent health and lifestyles. These characteristics prompted us to attempt a geographical investigation of data from a national survey on adolescent health conducted between 1992 and $1993^{14}$. This attempt was all the more difficult as the sample was schoolbased and not strictly random. Thus, the purpose of this paper is:

- to discuss the methodological problem raised by using a school-based survey dataset not originally gathered for the purpose of geographical representation;

- to show some of the results which were obtained, how they could be used and interpreted as well as the limits of this approach.

\section{Methods}

After briefly outlining the method which was used for the survey and which was previously published in this journal ${ }^{15}$, we will discuss several methodological steps which were dealt with to achieve a geographical representation of the results.

\section{The design of the survey}

The Swiss Multicenter Adolescent Survey on Health (so-called "SMASH" study) was conducted in Switzerland's three language communities during the years 1992 and 1993. Using one-step cluster sampling (stratification by educational background, grade and region) 9268 in-school adolescents were reached (5275 boys; 3993 girls), aged 15 to 19 years; they answered a paper and pencil anonymous selfadministered questionnaire. In Switzerland, it is estimated that about $90 \%$ of 15 - to 19-year-old teenagers can be reached through such a school survey ${ }^{15}$. The global rate of absent pupils was $5 \%$. Only two individuals refused to answer the questionnaire and answer rates varied between 92 and $98 \%$. The questionnaire was presented by professionals external to the school in order to ensure confidentiality. It included 80 questions targeting health attitudes and behaviour, health care utilisation, and lifestyles. Most of the questions were derived from similar surveys and had been discussed and cleared by a group of professionals and adolescents. The protocol had been reviewed by the Ethics Commission of the Faculty of Medicine of Lausanne University. All univariate and multivariate analyses were performed using a SPSS datafile.
Three main issues had to be addressed to adapt the dataset to a geographical utilisation, i.e.:

- determining how to divide the total surface area of Switzerland into reliable and meaningful subunits

- since the sample was not random, minimising the impact of sample differences across the subunits (weighting procedures)

- choosing the most suitable method to discretise the values of each variable into several classes so as to maximise inter-group differences and minimise intragroup differences.

\section{Dividing the sample into meaningful spatial subunits}

The choice of sound subunits is one of the main tasks of the geographer. An important issue is the size of the units: a sufficient number of subjects has to be included in each unit, but simultaneously, the units also must be as small as possible to allow for a significant geographical analysis. Also, the choice has to be meaningful in terms of the underlying social and political structure of each unit. The decoupage has to correspond to the way the health care or educational system is built within the country.

In our study, two items regarding the location of the participants were available: on the one hand, the name of the canton where the pupils lived, and on the other hand the name of the canton where they attended school (in some instances, pupils have to cross a cantonal border to go to school). As most of the accessible statistical data in Switzerland are based on the location of the home, we elected to use this criterion. As the sample comprised around 10000 participants, a detailed analysis per district would have been impossible. Even at the cantonal level, we were faced with the fact that cantons differ widely in size and that, in our sample, some of them had only 80 subjects while others had up to 1098 individuals! We thus had to aggregate some of the samples from several small cantons. The aggregation can be done under two conditions: first, the samples of cantons which are merged have to possess similar characteristics in terms of the linguistic, socio-economic and political background. Second, the subsamples to be aggregated have to be similar in terms of the rates of answers given in the main domains of the survey: we checked for these similarities using recoded dummy variables $^{\text {a }}$ using tests taking into account parametric and non-parametric distributions such as the Wilcoxon test ${ }^{3}$. Taking into account the distribution of the values of the variables, we calculated that each geographical subsample had to include at least 400 subjects to allow for the

\footnotetext{
a Sleep problems: $1=$ never or sometimes, $2=$ often or quite often; sports practice: $1=>1$ time a week, $2=<1$ time a week; use of cannabis: $1=>2$ times in one's life, $2=0-2$ times in one's life
} 
observation of differences statistically significant at the $p<0.05$ level. By the end of the process, 14 subunits were created, which represent less than the total number of cantons in Switzerland (24 cantons). The larger cantons were left as they were, while the smaller ones were merged provided they were contiguous. In one or two cases we had to keep fewer than 400 subjects in a separate unit because the aggregation would make no sense, taking into account linguistic, geographical or social criteria.

\section{Weighting procedures}

The structure of the samples across the units was not quite comparable. For instance, the fact that in some regions the girls had been over-represented and in others under-represented may have affected the overall analysis, since we know that girls' behaviour differs from boys' in several areas such as eating habits and sports activity ${ }^{14}$. The same holds true as

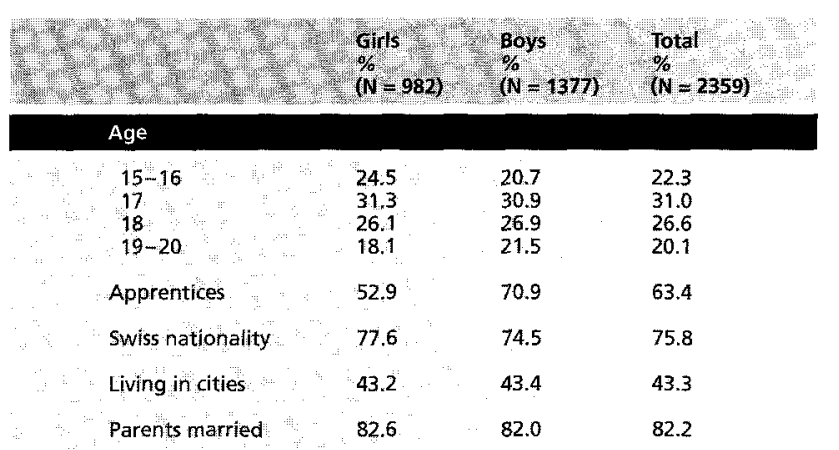

far as the partition between teenagers enrolled in high school or apprenticeship is concerned ${ }^{14}$. To minimise the impact of differences in the composition of the samples in the various subunits, the data were weighted and standardised according to age, sex, and professional background, which were considered as the three variables mostly influencing behaviour. Two reference structures were used for this procedure, i.e., the structure of each region's adolescent population, as available from the census (weighting) and the structure of the population of adolescents in the whole of Switzerland (standardisation) also available from the census. The reference in both cases was the population of inschool teenagers (we did not include drop-outs as they were not included in the survey). Both procedures brought similar results. Table 1 shows the main characteristics of the sample, while Table 2 gives an overview of the differences between the original and the weighted sample, by subunits and for three variables. As can be seen, there are no important differences in the crude rates (unweighted sample) and the corrected rates (weighted sample). For this reason, we chose to perform the discretisation of the values (with their inherent statistical calculation) on the raw data.

\section{Discretisation of the values (choice of the classes)}

To switch from answer rates to graphical maps, one has to use dummy variables and then divide the distribution of rates in the 14 subunits into several classes matched with discrete colours. This discretisation of the values in classes is not that commonplace ${ }^{16}$ : the classes should represent the

Table 1 Socio-demographic characteristics of the study sample

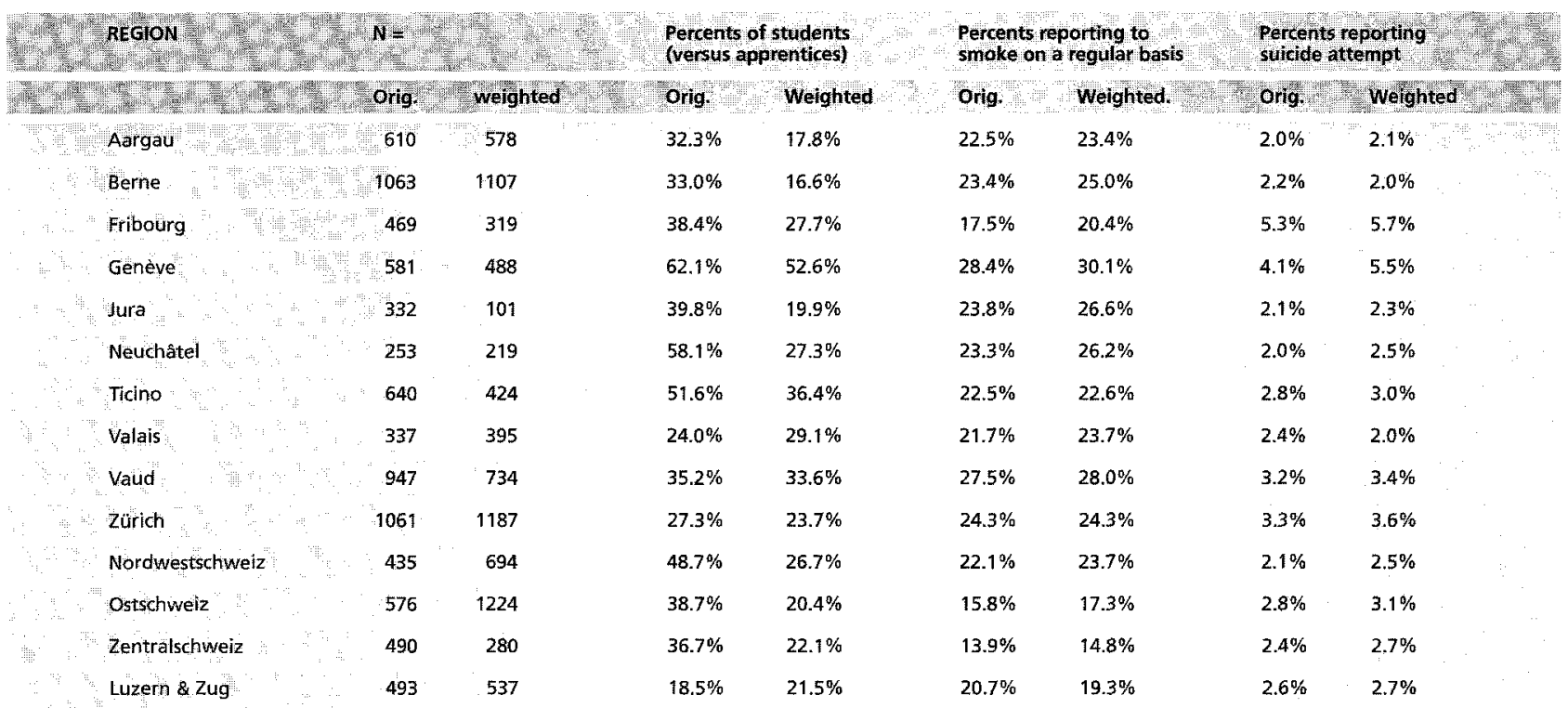

Table 2 Differences between original and weighted sub-samples in the 14 geographical areas 
main structure of the data, otherwise, the whole process looses much of its interest. Different methods can be used to create discrete classes. The "threshold" method we used 4,16 is an intuitive approach proposed by Jenks ${ }^{17}$, which creates several classes based on threshold values which minimise intra-class and maximise inter-class differences. The discretisation procedure was performed using the distribution of the rates in the 14 subunits and confidence intervals at 0.05 . The different classes were created in a specific way for each variable so that there was no statistically significant difference between two adjacent classes but at least a significant difference between non-adjacent classes. For some variables, the distribution of the rates across the subunits was quite uneven, while for others, it was so uniform that the division into several classes was not possible (Fig. 1B). In this latter case, the observed inter-subunit differences did not allow for the creation of five classes with statistically significant differences so that only two to four classes were used.

\section{Cluster analyses}

In an attempt to have an overall picture of the geographical distribution of the whole set of variables across the country, we performed a cluster analysis ${ }^{18,19}$ : this procedure aggregates those regions (cantons and groups of cantons) which display the most similar degree of overall rates. In other words, this hierarchical classification merges the regions (subunits) which possess the same characteristics in separate groups (displayed in black and white on the map), and thus (like for the discretisation process but at a higher level) maximises the inter-group and minimises the intra-group differences. This procedure was run using the "cluster analysis" SPSS.

\section{Results}

The detailed results have been published as a report entitled "Atlas of Adolescent Health in Switzerland" ${ }^{20}$. It gives a detailed description of the methods and 24 maps covering the main health and lifestyle indicators, including reported sense of well-being, reported use of health services (including hospitalisations), use of medications, reported rates of accidents, of substance use, of sexual behaviour, feelings of nervousness and depression as well as suicidal behaviour.

As can be expected, the distribution of the rates among the 14 subunits is different from one indicator to the other. For instance, Figure 2 shows the distribution of the use of cannabis in Switzerland: it shows that this behaviour tends to affect mostly the large cities of the country (Zurich, "Nordwestschweiz" which mainly includes the cities of Basel,
Geneva). However, the differences between non-adjacent classes do exhibit significant differences of rates. Figure 3 gives the distribution of the rates of intensive practice of sports (belonging to a sports club or practising sports intensively at least three times a week): the distribution across the whole nation is quite even. Figure 4, which pertains to the reported prevalence of sleep problems, brings another type of distribution, showing a clear difference between the French-speaking part (western Switzerland) and the German-speaking part (eastern cantons).

To which extent is the final distribution used by us valid? One way to answer this question is to look for other indicators which might be expected to exhibit a similar distribution. For instance, in the area of substance use, we compared our data with those of the police (occurrence of cannabis seizure or rates of sentences for hard drug use); in the area of use of health services we relied on data from insurance companies, whereas in the area of accidents, we had access to the data from the Swiss Bureau for Injury Prevention. In most of the cases, the two distributions (our data and official data) largely overlapped.

Figure 5 shows the results of the cluster analysis (hierarchical classification). For people familiar with the cultural background of Switzerland, it is interesting to note that in the three- and four-group partitions, the status of the Germanspeaking part of Switzerland is quite homogeneous while there are differences between the rural and the urban French-speaking cantons. It is only at the level of the partition in five groups that differences within the German-speaking part of the country appear. In other words, although the German-speaking part of Switzerland also comprises populated urban cantons and small rural cantons, there seem to be fewer differences between them than within the Frenchspeaking part of the country. Also, in the map showing a partition into three groups, the Italian-speaking subunit does not appear as a separate entity, i. e., it displays similar rates black and white - as the French-speaking urban cantons (a Latin-vs German-born cultural background).

\section{Discussion}

Whereas most available atlases are derived from population-based data (i. e. mortality rates), this research documents the feasibility of using self-reported data from a schoolbased survey. The presentation of data on black and white

Figure 1 Distribution of the rates in the 14 sub-units for three variables (figure $A$ : rates of cannabis use; figure $B$ : rates of sports activity; figure $C$ : rates of sleep problems) 


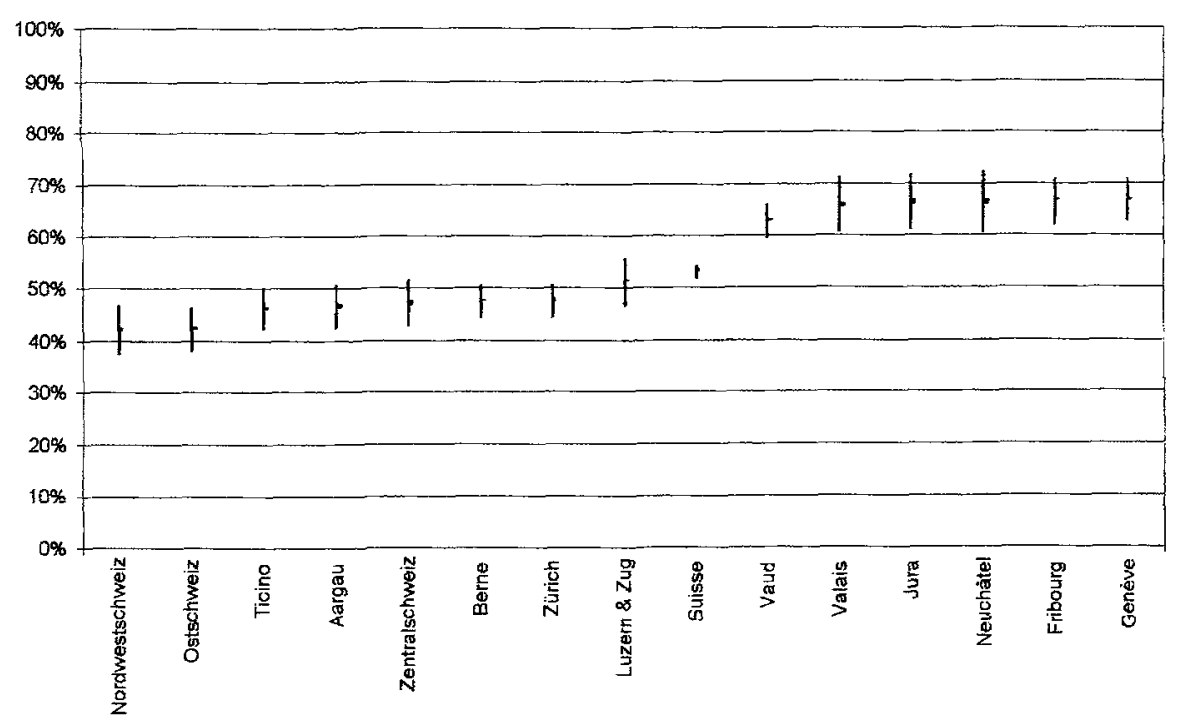

A

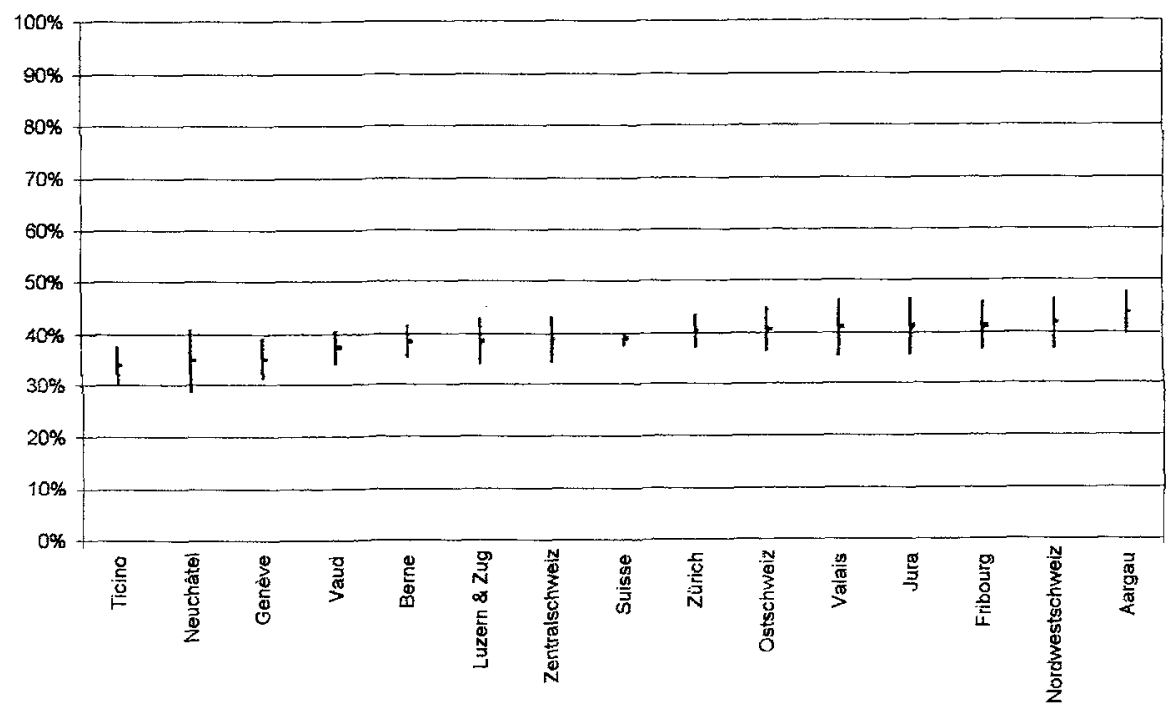

B
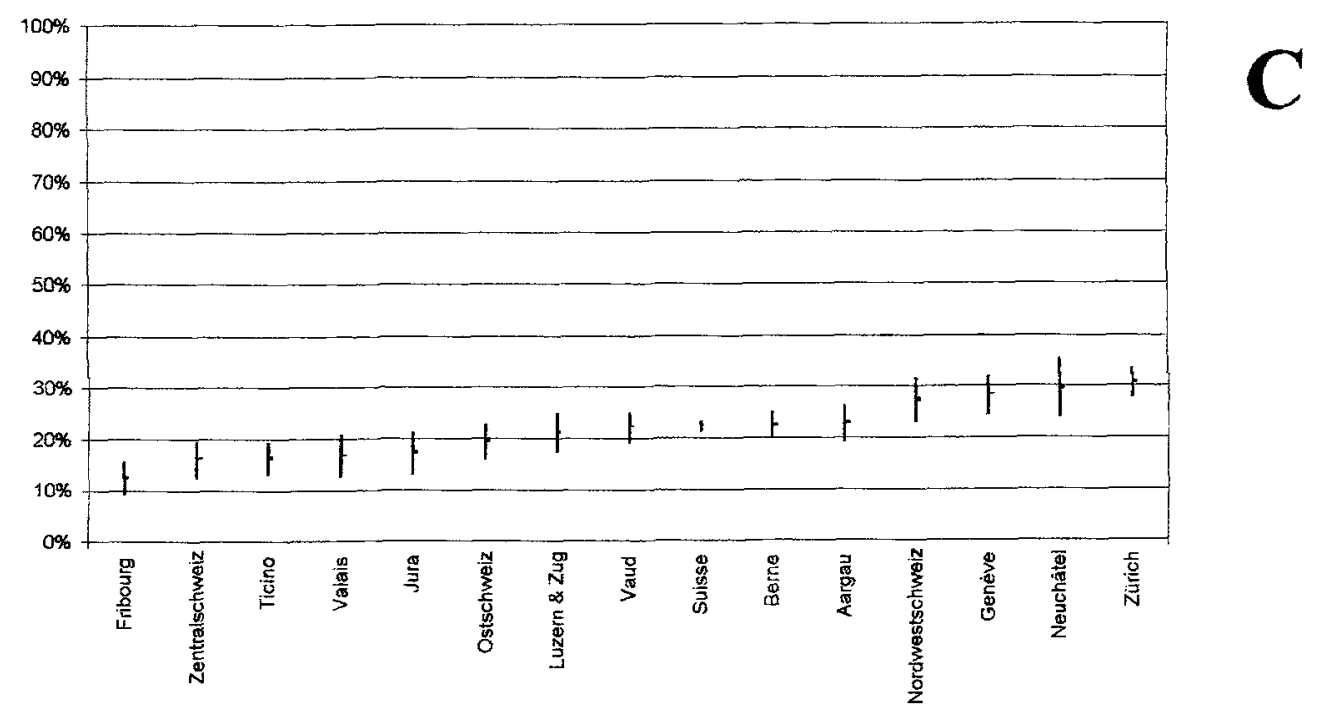


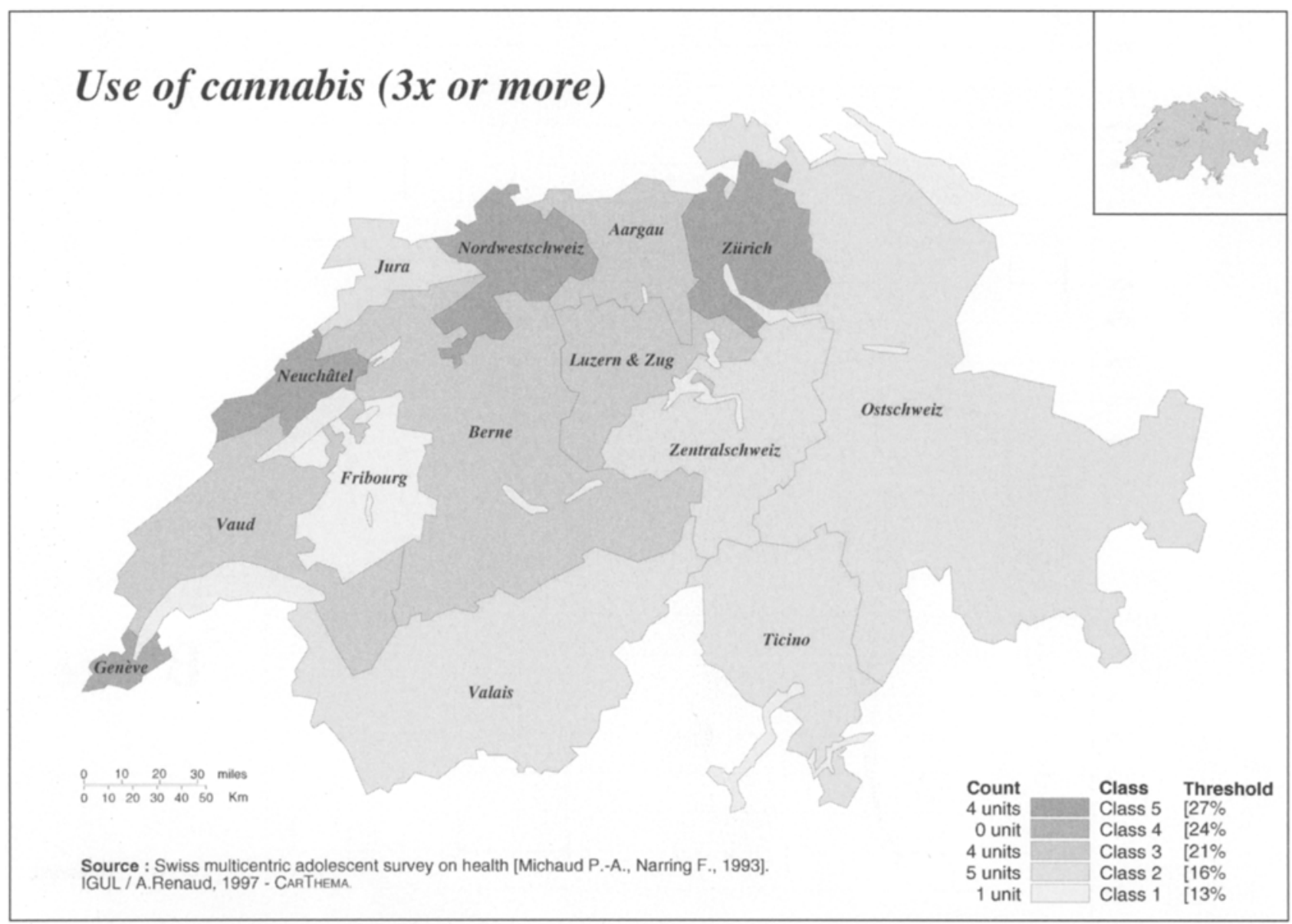

Figure 2 Map displaying the repartition of various rates of respondents reporting cannabis use in the 14 selected regions

maps provides a unique opportunity of generating hypotheses as to the causes of differences across cantons in a multicultural country. As to the methods we used, several comments need to be made.

First, to what extent are the answers given by the subjects valid and reliable? This problem, which is common to any school-based survey, has already been discussed elsewhere ${ }^{15}$. Suffice it to say that, although the questionnaire was not subjected to a validation process, it included many questions used in other similar research projects, and has been reviewed by a panel of experts and young people and pretested. In fact, the validity of the answers derives as much if not more from the way the survey was implemented in the schools than from the wording of the questions: we were very careful to explain the aims of the study to the subjects to gain their confidence; also, the questionnaire was completely anonymous and presented by people outside the school which should have alleviated any source of resistance from the young people. As in any school-based survey, our sample did not include pupils absent on the day of the sur- vey $(5 \%)$, neither those people who dropped out of school earlier, who constitute 10 to $20 \%$ of the population of 15 - to 19-year-olds in Switzerland. In other publications ${ }^{21,22}$, we have shown that these teenagers differ in several respects from the subjects included in the survey. Thus, the conclusion drawn from our study cannot be extrapolated automatically to all young people in Switzerland.

Another problem raised by our geographical analysis is the issue linked to the choice of the size and locations of the regions: the general tendency is to favour a multitude of small units instead of larger ones, which do not allow for meaningful geographical analysis ${ }^{19}$. However, we were limited by the overall size of our sample and thus kept a small number of subunits which allowed us to display significant differences: in delineating these units, we relied not only on the purely geographical characteristics of the regions (contiguity; mountains versus plain) but also on common versus diverse political and socio-economic factors, thus taking into account the social meaning of the space ${ }^{13}$. Another way to look at the respective role of personal/family factors versus 


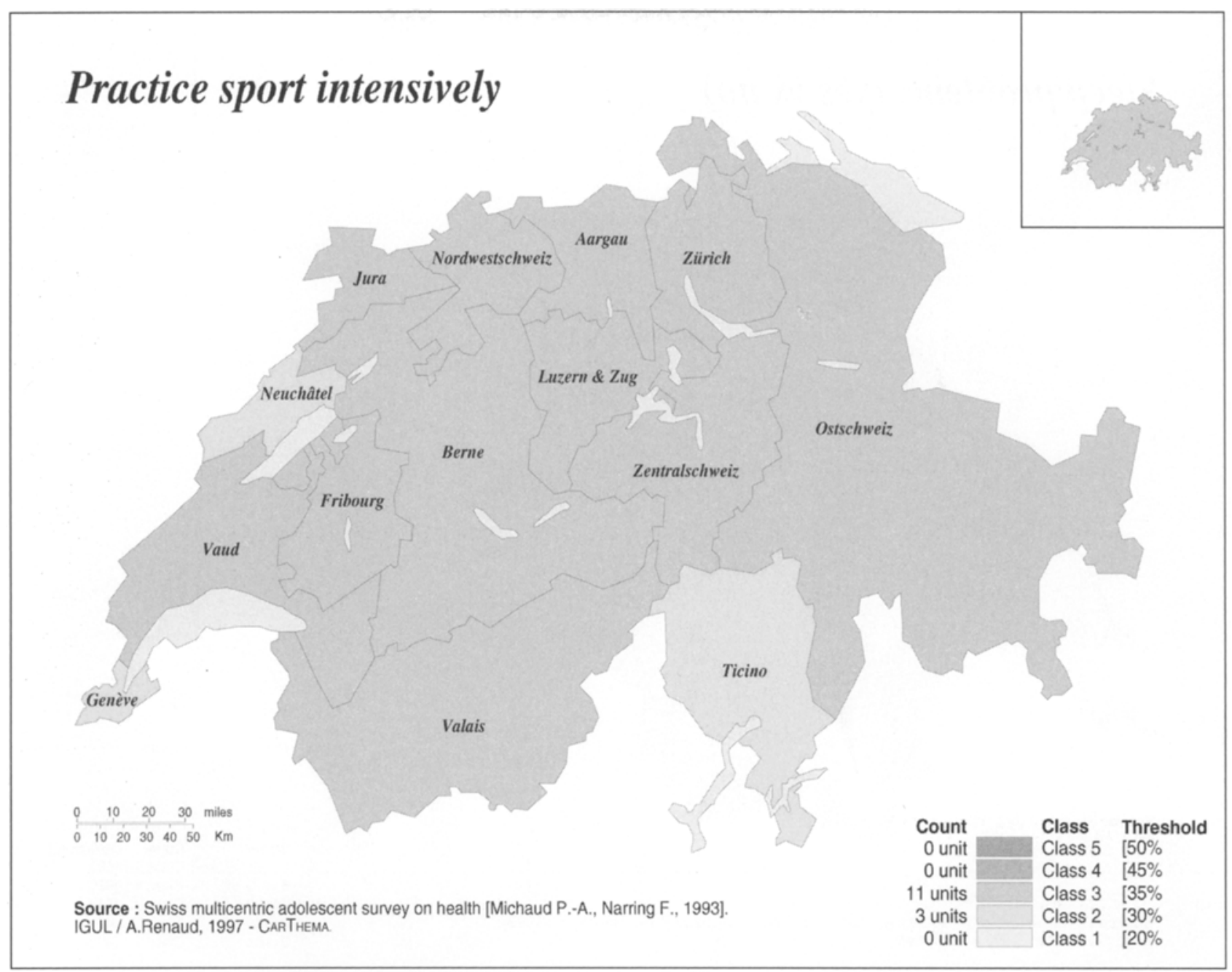

Figure 3 Map displaying the repartition of various rates of adolescents engaging in regular sports activity, in the 14 selected regions

neighbourhood/geographical factors would have been to rely on the multilevel modelling approach ${ }^{9-11}$.

In many instances when gender, age, or other socio-demographic characteristics were distributed unevenly, the researchers had to choose whether to use weighted or unweighted samples; in fact, in our survey, the differences we found were mostly nonsignificant and the discretization procedures gave the same distribution in both weighted and unweighted samples, which led us to make our statistical analyses on raw data. This absence of difference is probably due to the fact that the whole sample was selected using one-step cluster sampling (stratification by educational background, grade, and region).

Finally, the way we classified the results into two to five classes (the 2-5 of the maps) deserves consideration: whereas most of the authors rely on pure mathematical calculation, this was not appropriate in our case since many of the vari- ables did not show a normal distribution. Also, the number of the subjects did not allow for the calculation of enough statistically different classes. The approach we used merged the units possessing a similar degree of rates and set the threshold where "breaks" in the distribution of the rates are observed. This intuitive method was the most appropriate in the situation of small samples with only several units available ${ }^{17,23}$.

What are the lessons to be learned from this attempt? First, it shows that it is possible to address the issue of the geographical distribution of indicators other than the traditional population-based mortality and morbidity rates such as health attitudes, well-being, and reported lifestyles, i.e., indicators which are of prime importance when planning health services and prevention programmes for adolescents. However, the use of data from surveys needs a lot of statistical work to allow for sound nonbiased comparisons, especially when using results from nonrandom samples. 


\section{Sleep problems (yes vs no)}

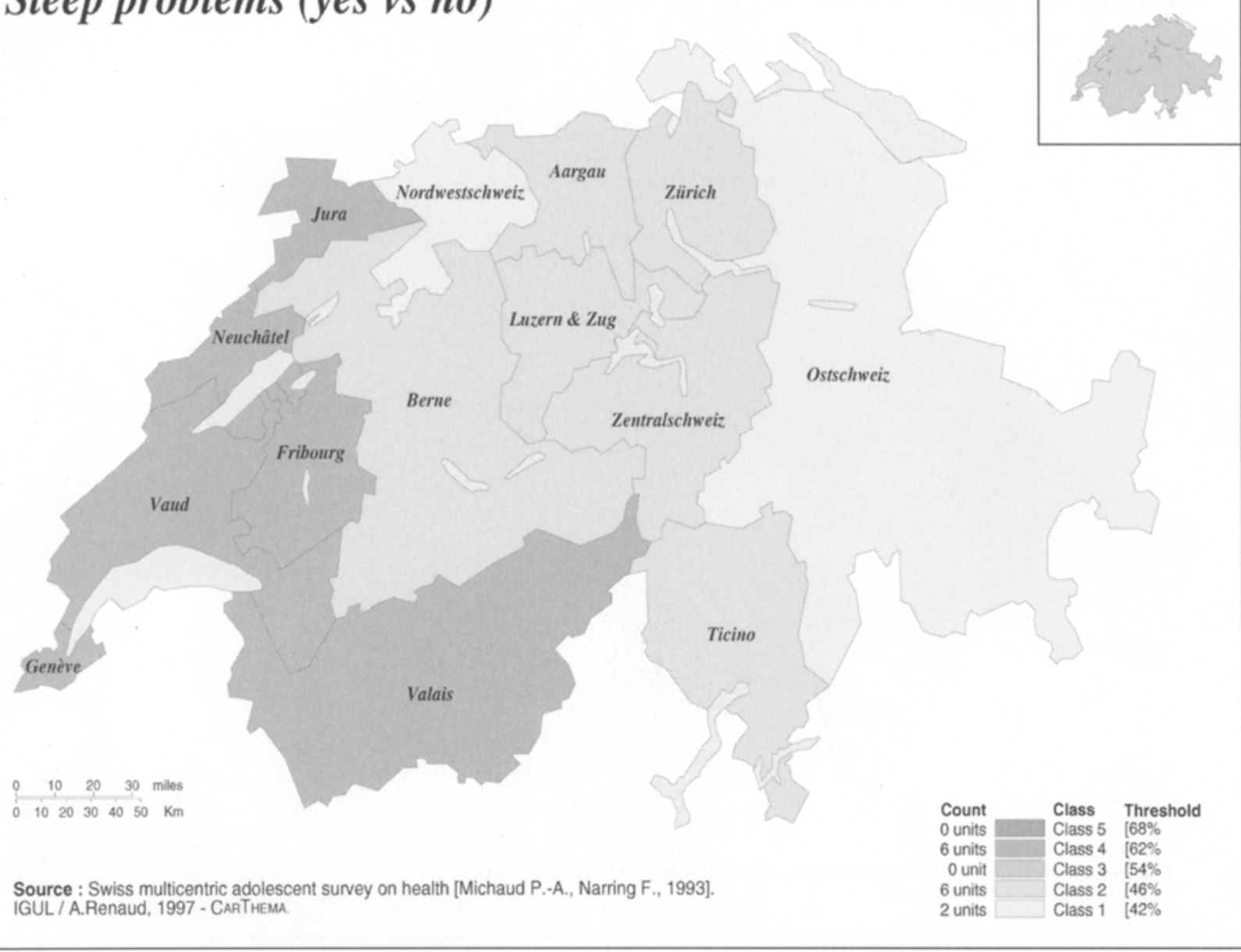

Figure 4 Map displaying the repartition of various rates of adolescents reporting sleep problems in the 14 selected regions

The distribution of the rates within Switzerland varies according to the indicator which is studied: as far as mental health and school results are concerned, the most striking differences appear between Switzerland's two main language communities, whereas the delimitation line for substance use is between rural and urban regions, whatever the language spoken. For some indicators like regular sports activity, the allotment is uniform. These various distribution patterns raise interesting hypotheses as to the respective influence of teaching systems and cultural views on health: for example, why are the rates for school difficulties, sleep problems, perceived stress, and use of psychoactive medication distributed in the same way? Is it linked with the school system or the attitudes towards school, or other educational or cultural factors? Why is the use of cannabis spread throughout the French-speaking part of Switzerland and limited to the cities in the German-speaking part of the country? Is it a question of availability or of education? Or are the prevention programmes more effective in certain parts of the country? Indeed, one has to remember that the data were all selfreported answers so that disparities may also be due to the way adolescents perceive their problems and situations and not only to actual dissimilarities in health status. Nevertheless, these contrasts in perception have to be taken into account too when planning programmes for teenagers.

There are several ways to draw an overall picture of the geographical inequality in the distribution of health indicators $^{22}$ : one can rely on plain visual comparisons of the maps, or on statistical analyses such as clustering ${ }^{23}$, which we did. The relevance of the clustering approach is that it provides further hypotheses as to the respective weight of different types of geographical (in the broader sense), political, economic, social, educational, and cultural characteristics of the regions of a country. For instance, we found that the most striking factor 

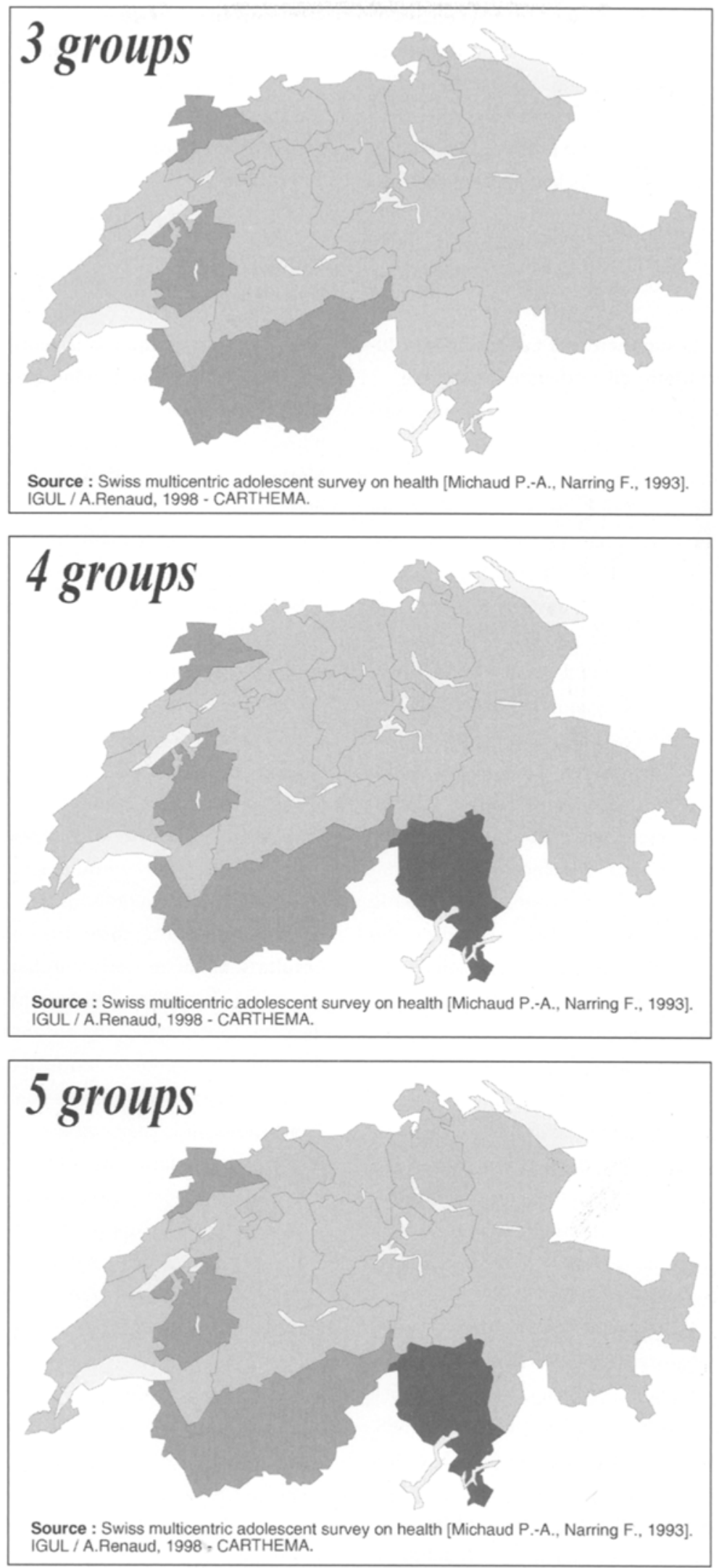

Figure 5 Cluster analyses: map showing the aggregation of those regions which display the most similar degree of overall rates (hierarchical classification for three, four and five aggregated regions) 
which emerges is the language spoken - with the cultural background which is necessarily associated with it - and that other geographical factors (mountain versus plain) or economic factors (rich versus poor regions) play a less important role.

We are not aware of similar analyses and thus could not compare our method with other groups. As specified in the pre-

Zusammentassung

Geografische Analyse der Gesundheit und Lebenstile von Jugendlichen in der Schweiz: Methodik und erste Ergebnisse

Hintergrund: Anhand der Ergebnisse einer nationalen Untersuchung zum Gesundheiszzustand der Jugendicher wird eine geogratischa Antyse awsgearbettet.

Methoden: Jugendithe zwischen 15 und 19 bhers, die ent wymnasium oder ane Barutsschulg besuchen $(N=327$ Jungen und 3993 Mảdcher haben Fragen zu hrem Gesundhetswustand und threm Lebenstil beantworte Der dafur ausgeabeikete Fragebogen war anonym und wurde von den Jugendichen

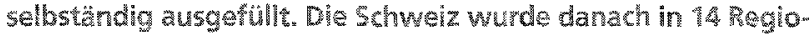
nen unterteit, die jeweils sin Minimum an 400 Beiragten entw hatten. Den grösseren Kantonen wurde elin aigene Region

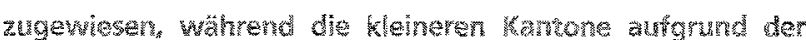
sprathichen, geografischen und sozio-kuturallen Ambichm keiten zu Einheiten zusammengefasst wurden. Un tie Auswhrkung der Unterschidede in der Zusammensetumg der Untermuster so gering wis moglich zu hatsen, wurden dese gewichter, indem die Vertellung nach Geschedh, Aiter und Abertsumeld einbezoget wurde. Fur jedo der Variablen wur den Antworkategonen asugearbeitet (Diskretitatomsprozess).

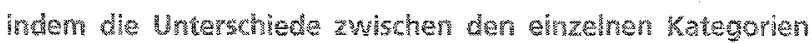

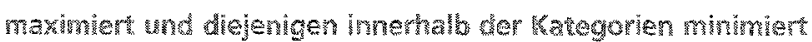
worden sined.

Resultate: Dieverschedenes Wariablen lassen untershiediche Verkilungsstrukturen erkenen. Der Drogenkonsum warlert vor allem zwischen der Land-und Stadreglonen, whistrend sich Unterschiede in Bezug aut den memtalen Gesundhehszstand vor allem zwischer den deusch bzw franzosisch prem chenden Reoionen festrenlen lassen.

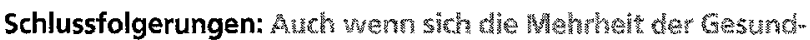

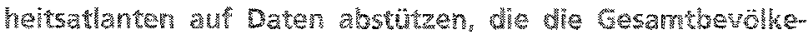
rung betreffen, beweist disse Untarsuchung, dass es möglich ist. die Daten ainer Betragung tur eine geografische Darstel lung wer Bevolkerung zw verwenden. Die durch die vorge-

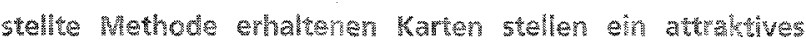
Mitcel dar, um Hypothesen in Bezug aur die Unterschede zwschen Regionen aufzustellen, vor allem wenm es sich dabei um enn muthuturelles Land wis die Schweiz handel. sentation of the results, we found an overall good correlation between the distribution of our self-reported rates and other health indicators available from insurance companies, state agencies, and health institutions. We believe that this geographical approach will prove useful in the future.

Résumé

Analyse géographique de la santé et des styles de vie des adolescents en Suisse: méthodologie et premiers résultats

Objectifs: Présenter une analyse géographique des résultats dune enquête natonale sur la santé des adolescents.

Méthodes: Des jeunes de 15 a 99 ans \#rétuentent des gymnases

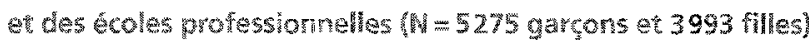
ont repondu a un questionmaire anonyme et autondodmistré centré sur la santé et les styles de vie. La suissct a cté subdivisée en 14 régions comprenant un minimum de 400 sulets: certains cantons foment en eux-mêre ure région, alops que les echanitums des plus petits cantons ont té re. groupes en unites aux caracteristiques lngurvicus gés

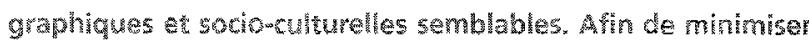

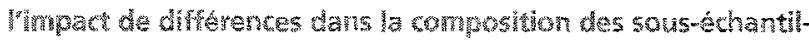
lons, ceukri ont âs ponderés an tenant compte de la distribution par sexe, par âge par milieu professionnel. Pour chacune des variables, on a regroupé les régions par un processus de "discrétisation" maximisan les différences interagroups at minimisant les diftzirances intra-groupe.

Résultats: Les analyses font apparatre des differerces structurelles selon les themes da sante abordés: I ugage de drogue va-

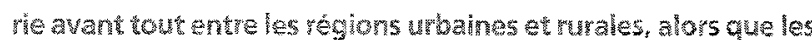

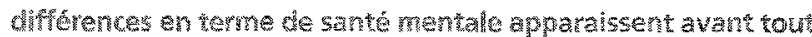
entre les régions de suisse romande ot de suisse alemanique.

Conclusions: Sil la majonté des atlas de santé sont vant tout fondes sur des bassa de domees exhaustives, co arravall démontre guril est postikle dutuliser les donnecs d"une enquete pour foumir une rrorésentation géographique da la santé drune population. Lutlisation de cartes constituse wn moyen

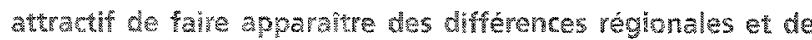

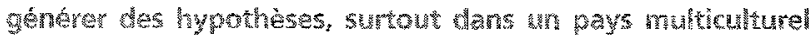
commelu Suisse. 


\section{References}

1 Picheral H. La géographie de la santé. In: Bailly A, ed. Les concepts de la géographie humaine. Paris: Masson 1991: 173-80.

2 Lucas-Gabrielli V, Tonnelier F, Vigneron E. Une typologie des paysages socio-sanitaires en France. Paris: CREDES, 1998.

3 Verhasselt $Y$. Geography of health: some trends and perspective. Soc Sci Med 1993; 36: 119-23.

4 Gordon A, Womersley J. The use of mapping in public health and planning health services. J Publ Health Med 1997; 19: $139-47$.

5 Kaplan GA, Pamuk ER, Lynch JW, Cohen $R D$, Balfour. $I L$. Inequality in income and mortality in the United States: analysis of mortality and potential pathways. BMJ 1996; 312: 999-1003.

6 Briancon S, Castello, Hilico C, Schléret Y. Atlas de la mortalité en Lorraine 1980-1984. Nancy: INSEE, 1989: 1-14.

7 Bopp M, Schüler G. Atlas der Krebsmortalität in der Schweiz 1970-1995. Basel: Birkhäuser, 1997.

8 Besson Simko C, Vader JP, Dupriez K, Burnand B, Koehn V, Paccaud F. A propos des "small area variations" opérations pour fracture de hanche dans le canton de Vaud. Schweiz Med Wschr 1994; 124: 2181-7.

9 Duncan C, Jones K, Moon G. Do places matter? A multi-level analysis of regional variations in health-related behavior in Britain. Soc Sci Med 1993; 37: 725-33.
10 Duncan C, Jones K, Moon G. Psychiatric morbidity: a multilevel approach to regional variations in the UK. J Epidemiol Community Health 1995; 49: 290-5.

11 Reading $R$, Langford IH, Haynes $R$, Lovett $A$. Accidents to preschool children: comparing family and neighbourhood risk factors. Soc Sci Med 1999; 48: 321-30.

12 World Health Organization. The health of young people. Geneva: WHO 1994.

13 Kearns $R$, Joseph AE. Space in its place: developing the link in medical geography. Soc Sci Med 1993; 37: 711-7.

14 Narring F, Tschumper AM, Michaud PA, Vanetta F, Meyer $R$, Wydler $H$. La santé des adolescents en Suisse. Rapport d'une enquête nationale sur la santé et les styles de vie des 15-20 ans. Lausanne: Institut universitaire de médecine sociale et préventive, 1994.

15 Narring $F$, Michaud PA. Methodological issues in adolescent health surveys: the case of the Swiss multicenter adolescent survey on health. Soz Praventivmed 1995; 40. $172-82$

16 Cauvin C, Reymond H, Serradj A. Discrétisation et représentation cartographique. Montpellier: GIP Reclus, 1987.

17 Jenks GF. Optimal data classification for choropleth maps. Kansas: University of Kansas, 1977.

18 Lebart L, Morineau A, Piron M. Statistique exploratoire multidimensionnelle. Paris: Dunod, 1997.
19 Sanders $L$. L'analyse statistique des données en géographie. Montpellier: AlidadeReclus, 1990.

20 Renaud A. Atlas de la santé des adolescents en Suisse. Mémoire de Licence. Lausanne: Institut de géographie de l'Université de Lausanne, 1998.

21 Michaud PA, Delbos-Piot I, Narring C. Silent dropouts in health surveys: are nonrespondent absent teenagers different from those who participate in school-based health surveys? J Adolesc Health 1998; 22: 326-33.

22 Delbos-Piot I, Narring F, Michaud PA. La santé des jeunes hors du système de formation: comparaison entres jeunes hors formation et en formation dans le cadre de l'enquête sur la santé et les styles de vie des 15-20 ans en Suisse Romande. Santé publique 1995; 1: 59-72.

23 Walter $S D$. Visual and statistical assessment of spatial clustering in mapped data. Stat Med 1993; 12: 1275-91.

Address for correspondence

Prof. Pierre-André Michaud MD

IUMSP

Bugnon 17

CH-1005 Lausanne

Tel.: ++4121314 7288

Fax: ++41213147244

e-mail:

Pierre-Andre.Michaud@inst.hospvd.ch 